\title{
The relative influence of Inter-generational co-residence on Healthcare Market and Labor Market Outcomes in Post Affordable-Care-Act USA: Evidence from the 2015-2016 National Health Interview Surveys
}

\author{
Ibrahim Niankara \\ College of Business, Al Ain University of Science and Technology, P.O. Box: 112612, Abu Dhabi, UAE; Tel: \\ +97124444696 Ext: 539 ; Fax: +97124444304; E-mail: ibrahim.niankara@aau.ac.ae
}

\begin{abstract}
This paper investigates the effects of Inter-generational co-residence on health care market, and labor market outcomes, to see whether or not living under the same roof with at least one parent matters in health care market, and labor market behaviors in post-Affordable-Care Act (ACA) USA. The adopted analytical strategy involves not only looking at the gender differences in co-residence, and its effects on outcomes in the two markets, but also accounting for co-residence endogeneity following the recent literature. Unlike the recent literature that relies on instrumental variables methods, this study adopts a switching regression approach, defining inter-generational co-residence as an endogenous selection process using a binary probit equation, and modeled jointly with the extensive margins and intensive margins in the two markets. This novel approach results in a recursive trivariate probit model for each market, and estimated using penalized maximum likelihood methods.

The results suggest that ACA by reorganizing the US health care market, seems to have reduced significantly disparities in health care access among males and females based on race, region of residence, place of birth, and citizenship. However not only do we observe significant differences in inter-generational co-residence status between males and females, we also find significant inequalities in the effects of coresidence on health care market, and labor market outcomes. In fact, co-residence is found to increase health care expenditure by $56.7 \%$ among females, while this figure increases to $74.2 \%$ among males. In addition co-residing individuals, while spending $69.7 \%$ more on health care annually are 1.22 times more likely to access health care, but $31 \%$ less likely to use health care intensively during the year. In the labor market, co-residence is found to reduce significantly hours of weekly labor supplied by $41 \%$ for females, and $55.6 \%$ for males. Furthermore co-residing individuals, while not significantly different in their likelihood of labor force participation, are 1.52 times less likely to work full time once they decide to participate, and also spend about $55.4 \%$ less time working in the labor market in post-ACA USA.
\end{abstract}

Keywords: Affordable Care Act, access to care, co-residence, labor supply, medical expenditure JEL: D1, I11, I12, J12, J21, J22 


\section{Introduction}

Although many factors shape global residence patterns, Modernization Theory emphasizes the role of economic development and industrialization as the primary determinants of trends in intergenerational co-residence (Peng, 2009; Bordoloi and Das, 2017). These relationships typically involve both affective ties and more instrumental forms of support such as financial resources or child care(Mandell and Kim, 2017). In reporting on inter-generational co-residence in the USA between 1850 to 2000, Ruggles (2007) notes a historical decline which was justified using two major hypothesis: The affluence hypothesis and the economic development hypothesis.

The affluence hypothesis as the consensus view of social scientists in recent decades, posits that rising economic resources of the aged increasingly allowed them to maintain independent residences (McGarry and Schoeni, 2000), while the economic development hypothesis, embraced by earlier generations of theorists and policymakers, contends that rising wage-labor opportunities and the declining importance of agricultural inheritance reduced the incentives for members of the younger generation to remain in their parents' homes (Rosenfeld, 2006). A more recent evaluation of US inter-generational co-residence patterns by Ruggles (2011) suggests its probable reciprocal nature between generations than principally a means of old-age support. A view also shared by (Grundy, 2005).

As a social phenomenon however, inter-generational family relationships such as co-residence reflect adaptations to the prevailing state of economic and cultural conditions Compton and Pollak, 2015). And as recent studies show, inter-generational relationships between adult children and their parents are increasingly becoming important to Americans not only because of rising marital instability and broader demographic shifts (Swartz, 2009), but also because of economic crises (Keene and Batson, 2010).

In fact, the global financial crisis of 2008 which originated in the US, put a major dip on wagelabor opportunities globally (Cho and Newhouse, 2013; Khanna and Newhouse, 2013; Bruno et al., 2017) including in the USA (Verick, 2009), and thus contributed to weakening both the economic development hypothesis and the affluence hypothesis of reduced inter-generational co-residence in recent years (Keene and Batson, 2010). A report on income, poverty, and health insurance coverage in the United States based on information collected in the 2011 and earlier Current Population Survey Annual Social and Economic Supplements (CPS ASEC) conducted by the U.S. Census Bureau (Proctor, 2016) shows that between 2009 and 2010, real median household income declined, while both poverty rate and the number of people without insurance increased. Young people were far more affected by the employment crises than the elder; long term unemployment for young workers were significantly harmed resulting in "discouraged workers" effects and social exclusion from labour markets (Tanveer Choudhry et al., 2012; Sorgente and Lanz, 2017). As a result, several policies were enacted in the US to mitigate the societal effects of the global recession(Verick and Islam, 2010). Among those policies were the ACA (Harrington, 2010; Sommers et al., 2012), which 
to this date is recognized as the biggest health policy change in US history after Medicare (Shaw et al., 2014) and Social Security which have contributed to the rise of the affluence hypothesis and the economic development hypothesis of reduced Inter-generational co-residence in the USA.

In Europe, Courtin and Avendano (2016) shows that in the context of high unemployment rates during the great recession of 2008, increased inter-generational exchange between adult children and older parents in the form of co-residence had positive mental health effects on older parents. In the US however, although Keene and Batson (2010) suggests that inter-generational co-residence responds to national economic conditions, no study to the best of our knowledge reports on the influence of inter-generational co-residence on health care market and labor market outcomes in the period post ACA enforcement. Therefore, the aim of the current analysis is simply to describe how the changes in US health policy framework through the ACA has been affecting the dynamics in the Health care market and labor market. The general question it seeks to address is:

Does living under the same roof with at least one parent matters in health care market, and labor market behaviors in post-Affordable-Care Act USA?

more specifically:

- Q1: Is the likelihood of inter-generational co-residence the same for males and females in the USA between 2015-2016?

- Q2: Does inter-generational co-residence significantly affect health care access, usage and expenditure in the USA between 2015-2016?

- Q3: Are the effects of inter-generational co-residence on health care access, usage and expenditure the same for males and females in the USA between 2015-2016?

- Q4: Does inter-generational co-residence significantly affect labor market participation, fulltime work status and time spent working in the USA between 2015-2016 ?

- Q5: Are the effects of inter-generational co-residence on labor market participation, full-time work status and time spent working the same for males and females in the USA between 2015-2016?

The maintained null hypothesis with respect to the above questions are:

- $H_{0}(1)$ : There are no significant differences in likelihood of inter-generational co-residence between males and females in post-ACA USA

- $H_{0}(2)$ : Inter-generational co-residence has no bearing in health care access, usage and expenditure in post-ACA USA 
- $H_{0}(3)$ : There are no gender inequalities in inter-generational co-residence effects on health care market outcomes in post-ACA USA

- $H_{0}(4)$ : Inter-generational co-residence has no bearing on labor market participation, full-time work status and time spent working in post-ACA USA

- $H_{0}(5)$ : There are no gender inequalities in inter-generational co-residence effects on labor market outcomes in post-ACA USA

In order to test the above five hypothesis and answer the raised questions, we use a pooled cross-sectional sample of the 2015 and 2016 National Health Interview surveys, since 2015 marks the starting point of ACA penalty enforcement since its introduction in 2010. Because different states have been implementing the act in different ways, we anticipate regional heterogeneity in ACA effects on Healthcare market and labor market outcomes in the US.

The rest of the analysis is organized as follows: Section 02 presents the legal, socio-political and contextual framework of the study; section 03 describes the behavioral economic model, while section 04 presents the econometric framework and model identification strategies. Section 05 proceeds to describe the data, while section 06 presents and discusses the results, and finally section 07 concludes the analysis.

\section{Legal, Socio-Political and Contextual Background}

\subsection{The Affordable Care Act (ACA)}

The Patient Protection and Affordable Care Act, more commonly referred to as "Obamacare" is the healthcare law passed by Congress on March 3, 2010 during the administration of President Barack Obama, with the aim of ensuring that most Americans can receive or buy health insurance (Harrington, 2010). Phased in over four years from 2011 to 2015, ACA constituted what is widely considered the most sweeping change to the U.S. healthcare system since Medicare and Medicaid were created in 1965 (Harrington, 2010; Even and Macpherson, 2016).

Together the individual mandate and company mandate of the Act changed not only healthcare sector dynamics, but also labor market dynamics in the US. In fact, the act allows insurance coverage of preventive care such as mammograms, checkups and screenings (Koh and Sebelius, 2010), which should grant more access and usage of preventive healthcare (Bauer et al., 2014). It also made gender based premium discrimination illegal, allowing women to pay the same health insurance premium costs as men "ceteris paribus" (Shaw et al., 2014).

The dependent coverage provision of the act requires insurers to allow dependents to remain under parental insurance coverage until they turn 26 (Barbaresco et al., 2015$)$, while the individual mandate requires each legal resident of the US to have some form of health insurance or face penalties(fees) by year 2015; The fee structure is $\$ 95$ per year for any uninsured adult (or $1 \%$ of 
annual income), for children this fee is reduced to $\$ 47.5$ per child per year, and to not exceed $\$ 285$ per year for an entire family. The act also led to the creation of the Health Insurance Market Place (HIMP), allowing individuals to shop for affordable coverages (Pollitz et al., 2015). In regards to the company mandate, the act through its SHOP (Small Business Health Option Program) provides tax credits for business that acquire coverage for their employees, and imposes the "Employers shared responsibility payment" to large companies (50 or more employees) that fail to provide "a minimum value standard" to their employees by the year 2015 .

\subsection{Health Market Outcomes in the USA}

Inter-generational co-residence effect on US healthcare market is assessed in terms of its influence on access to, usage of, and expenditure on healthcare in the US. Below we provide a brief description of the literature on these three aspects of the US healthcare Market.

\subsubsection{Access and Usage of Healthcare in the USA}

Prior to ACA, data shows that young adults represented the group with the highest rate of uninsured in the US at 29\% among individuals ages 18-24 and 27\% among those 25-34, compared to $19 \%$ for $35-44$ year olds and $14 \%$ for $45-64$ year olds (DeNavas-Walt, 2010). Health insurance coverage however, usually improves the potential to access preventive health services (Koh and Sebelius, 2010; Cohen and Martinez, 2014; Christopher and Caruso, 2015), while access to preventive recommended health services reduce the risks of chronic diseases (Koh et al., 2011), which represent the main causes of poor health, disability, and death, and account for most of health-care expenditures in the US(Bauer et al., 2014).

Early reports of ACA effects suggests that the dependent coverage provision increased the likelihood of young adults health insurance coverage(Proctor, 2016), access to primary care(Wallace and Sommers, 2015), excellent self-assessed health (Sommers et al., 2015), and low body mass index(Barbaresco et al., 2015). The gains for adults ages 19-25, continued to grow throughout 2011, with the largest gains recorded for unmarried adults, non-students, and men Sommers et al. (2012).

Health care services utilization in a population is affected by several factors including (1) socioeconomic status, (2) physician supply, (3) risk behaviors among members, (4) health status and (5) policies and beliefs (Morreale, 1998; Rosenstock, 2005). Focusing on the relative influence of the last factor, with regards to the usage of healthcare in the US, ACA enhances medicare coverage for preventive services by eliminating patient cost-sharing and introducing an "Annual Wellness Visit," (DiSantostefano, 2011; Dallmann-Papke and Scott, 2016) free-of-charge for seniors (Jensen et al., 2015). Although racial and regional disparities exist among young adult trauma patients (Scott et al., 2015), overall, the young adult mandate has contributed to improve the use of inpatient medical care (Antwi, Moriya and Simon, 2015; Han et al., 2015), while reducing unnecessary emergency department visits(Antwi, Moriya, Simon and Sommers, 2015) in this age 
group. With more than two-thirds of the US population overweight or obese Cecchini and Sassi, 2015), prevention interventions through ACA provides substantial savings potentials in the long term by significantly reducing the use of healthcare services and expenditure.

\subsubsection{Expenditure on Healthcare in the USA}

Prior to the ACA, in 2004 the United States spent $\$ 1.9$ trillion, or 16 percent of its gross domestic product (GDP) on health care; averaging to about $\$ 6,280$ for each man, woman, and child (Stanton and Rutherford, 2006). A comparative analysis of health expenditure relying on OECD's System of Health Accounts (SHA) data by Lorenzoni et al. (2014) shows that during the period of 2000 to 2011, the USA had the highest total and public health expenditure per person, and share of GDP spent on health care, of the examined countries. Out-of-pocket (OOP) health expenditure per person was higher than in other high-spending countries (Except Switzerland)(Baltagi and Moscone, 2010). The quality of care especially in the primary care sector, based on OECD Health care quality indicators, did not seem to justify however the observed higher health expenditure in the country (Jaffe and Frieden, 2014). Lorenzoni et al. (2014) however, report a sharp decline in health expenditure growth per person in the USA from 2000 to 2011, after adjusting for inflation. Although by 2012 , health spending reached $\$ 2.8$ trillion, or $\$ 8915$ per person, and accounted for $17.2 \%$ of gross domestic product(Jaffe and Frieden, 2014). Prevention interventions in 2010 had the potential to decrease total healthcare expenditure by up to $\$ 2$ billion (Cecchini and Sassi, 2015). After additionally controlling for household income, education, and employment (Chua and Sommers, 2014) reports that ACA dependent coverage provision is associated with improved protection against medical costs (a 3.7 percentage points reduction in out-of-pocket expenditure) among adults aged 19 to 25 years compared with older adults relatively unaffected by the law. Similarly, using difference-in-difference comparison between the near elderly (ages 60 to 65) and elderly enrolled in Medicare (ages 65 to 70), Allison (2017) reports a reduction in the odds of outof-pocket and total expenditures exceeding zero for the overall sample, but not the treatment group in 2014. As of 2016, national medical expenditure amounted to $\$ 3.3$ trillion or about $\$ 10,500$ per person, for the 325 million people living in the USA, and represented about $18 \%$ of the country's GDP (Phelps, 2017).

\subsection{Inter-generational co-residence and Labor Market Outcomes}

Inter-generational co-residence effect on labor market outcomes is assessed in terms of individuals labor supply decisions that is, the decision of whether or not to work (the extensive margin), and the decision of how many hours to work (Intensive margin). Several studies have looked at this effect especially for the case of female labor force participation. For example, Outside of the US, using data from china, Shen et al. (2016) reports that women co-residing with their parents are 27.9 percentage points more likely to work than those living apart, while women living with their parents in the same neighborhood are 34.9 percentage points more likely to work than those 
living in a different neighborhood. They also found that on average, co-residence or nearby residence with parents significantly increases women's work time by 20-26 hours per week. Conversely, Landmann et al. (2017) finds that co-residence, although insignificant, reduces female labor supply in Kyrgyzstan. In the US, using a pooled cross-sectional sample compiled from eleven years of the Panel Study of Income Dynamics, Kolodinsky and Shirey (2000) reports significantly different labor market outcomes for inter-generational co-residing females compared to their non-co-residing counterparts. Similarly, using the National Survey of Families and Households and the public use files of the U.S. Census Compton and Pollak (2014) found that the predicted probability of employment and labor force participation is 4-10 percentage points higher for married women with young children living in close proximity to their mothers or their mothers-in-law compared with those living further away.

Because of the interconnected relationships between health insurance, health, and labor market outcomes Madrian (2006); Rutledge (2016), the federal dependent coverage provision of the health insurance mandate has the potential to not only re-enforce inter-generational family relations, but also distort labor market activity and time allocation (Shrestha and Lenhart, 2015; Dolan, 2016; Lenhart and Shrestha, 2016; Duggan et al., 2017). In fact, relying on evidence from the American time use survey, Colman and Dave (2018) reports that ACA dependent coverage mandate decreases young adults labor supply, with the increased free time used for socializing, and educational and job-search activities. A similar decrease in labor supply is recorded by Depew (2015) at the intensive margin. On the other hand, using a triple-difference strategy and tax data to examine the impact of ACA on labor market outcomes, Heim et al. (2015) reports no substantial change. Similarly, In reviewing evidence over the five years of ACA implementation, Schoen (2016) concludes that the ACA has had no net negative economic impact and, in fact, has likely helped to stimulate growth by contributing to the slower rise in health care costs. Overall however, Gaudette et al. (2016) reports an inconclusive effect through a literature review on the lifetime consequences of early and midlife access to health insurance on labor market outcomes.

\section{The Behavioral Economic Model}

Our economic model of inter-generational co-residence, health care market, and labor market outcomes is grounded on the discrete choice modeling framework(Niankara, 2018), derived under Random Utility Theory (Azari et al., 2012; Manski, 1977). For this, we make two different assumptions about the process generating Inter-generational co-residence, allowing us to derive two distinctive models where one is a special case of the other, and obtained through a one dimensional restriction. The first model is derived under the assumption of endogenous co-residence effects yielding a trivariate sample selection model (TSSM) with a recursive system of three equations, while the second equation is derived under the assumption of exogenous co-residence effect producing a bivariate sample selection model (BSSM) with a recursive system of two equations. 


\subsection{The Random Utility Model with Endogenous Selection: TSSM}

In the endogenous formulation, we assume that the individual (Agent) contemplates participation in two markets $M_{i}$ for $(i=1,2)$, where $M_{1}=$ Health care market, and $M_{2}=$ Labor Market. For each market $M_{i}$, the individual is faced with three choice situations (or decisions) $D_{j}$ for $(j=0,1,2)$, where $D_{0}$ : should I co-reside with my parents or not ? (the selection process) $D_{1}$ : should i participate in the market or not? (extensive margin) $D_{2}$ : should i participate intensely or not? (intensive margin). For each decision $D_{j}$, the individual is faced with two alternatives $A_{k}$ for $(\mathrm{k}=0,1)$, where $A_{0}=$ no and $A_{1}=$ yes.

Therefore the individual's problem consists of choosing alternative $A_{k}$ in choice situation $D_{j}$ in market $M_{i}$ for all $(i=1,2),(j=0,1,2)$ and $(\mathrm{k}=0,1)$ based on the relative expected utility of the choices. That is, by the expected utility Theory (Mongin, 1997), there exist an additive random utility function (Hey and Orme, 1994; Niankara, 2017):

$$
U_{i j k}=V_{i j k}+\epsilon_{i j k}
$$

where $U_{i j k}$ is the utility of the $k^{t h}$ alternative in the $j^{t h}$ choice situation, within the $i^{t h}$ market. $V_{i j k}$ represents the deterministic components of the utility function, while $\epsilon_{i j k}$ represent the random components. Abstracting from the alternatives indice $k$ this function can be rewritten more explicitly, for all $(i=1,2)$ and $(j=0,1,2)$ as

$$
\begin{aligned}
& U_{i j 0}=V_{i j 0}+\epsilon_{i j 0}, \\
& U_{i j 1}=V_{i j 1}+\epsilon_{i j 1}
\end{aligned}
$$

Therefore, we observe the outcome $y_{i j}=1$, if and only if $U_{i j 1}>U_{i j 0}$, that is if alternative $A_{1}$ has the highest utility in the $j^{\text {th }}$ choice situation, within the $i^{\text {th }}$ market. Since the utility function has random components, this event is also random with probability represented as:

$$
\begin{aligned}
\operatorname{Pr}\left[y_{i j}=1\right] & =\operatorname{Pr}\left[U_{i j 1}>U_{i j 0}\right] \\
& =\operatorname{Pr}\left[V_{i j 1}+\epsilon_{i j 1}>V_{i j 0}+\epsilon_{i j 0}\right] \\
& =\operatorname{Pr}\left[\epsilon_{i j 0}-\epsilon_{i j 1}<-\left(V_{i j 0}-V_{i j 1}\right)\right] \\
& =F\left(V_{i j 0}-V_{i j 1}\right)
\end{aligned}
$$

where $F($.$) is the multivariate cumulative distribution function of the error differences \left(\epsilon_{i j 0}-\epsilon_{i j 1}\right)$, and giving

$$
\operatorname{Pr}\left[y_{i j}=1\right]=F\left(X_{j}^{\prime} \beta_{i j}\right) \text { if } V_{i j 0}-V_{i j 1}=X_{j}^{\prime} \beta_{i j}
$$

Furthermore, if we assume independence of the two markets, then the above equation(4) can be rewritten more explicitly as: 


$$
\begin{aligned}
& \operatorname{Pr}\left[y_{1 j}=1\right]=F\left(X_{j}^{\prime} \beta_{1 j}\right) \text { if } V_{1 j 0}-V_{1 j 1}=X_{j}^{\prime} \beta_{1 j} \\
& \operatorname{Pr}\left[y_{2 j}=1\right]=F\left(X_{j}^{\prime} \beta_{2 j}\right) \text { if } V_{2 j 0}-V_{2 j 1}=X_{j}^{\prime} \beta_{2 j}
\end{aligned}
$$

where $\operatorname{Pr}\left[y_{1 j}=1\right]$, and $\operatorname{Pr}\left[y_{2 j}=1\right]$ represent the choice probabilities in the health care market, and the labor market respectively. Both choice probabilities are tri-dimensional since $j=0,1,2$. As such, in each market we obtain a trivariate choice probability model describing the three decisions or choice situations $D_{j}$ for $(j=0,1,2)$. Different parametric distributions can be specified for the error differences $\left(\epsilon_{1 j 0}-\epsilon_{1 j 1}\right)$ and $\left(\epsilon_{2 j 0}-\epsilon_{2 j 1}\right)$, yielding different types of discrete choice models. If we assume $F()=.\Lambda($.$) , that is the multivariate type 1$ extreme value cumulative distribution, then we obtain the trivariate logistic regression model. If instead we assume $F()=.\Phi($.$) , that is$ the multivariate normal cumulative distribution, then we obtain the trivariate probit model. For the rest of the analysis we will assume the later such that for all $\mathrm{j}=0,1,2$ we have:

$$
\begin{aligned}
& \operatorname{Pr}\left[y_{1 j}=1\right]=F\left(X_{j}^{\prime} \beta_{1 j}\right)=\Phi\left(X_{j}^{\prime} \beta_{1 j}\right) \quad \text { For the Health Care Market } \\
& \operatorname{Pr}\left[y_{2 j}=1\right]=F\left(X_{j}^{\prime} \beta_{2 j}\right)=\Phi\left(X_{j}^{\prime} \beta_{2 j}\right) \quad \text { For the Labor Market }
\end{aligned}
$$

\subsection{The Random Utility Model with Exogenous Selection: BSSM}

The derivation of the exogenous case, is similar to that of the endogenous, as previously mentioned. However, because selection exogeneity implies that the co-residence decision is no longer under the control of the individual decision maker, we get a one dimensional restriction on the choice situations $j$, such that we no longer have $j=0,1,2$ as in the endogenous case, but instead $j=1,2$ only. with this restriction, the choice probabilities $\operatorname{Pr}\left[y_{1 j}=1\right]$, and $\operatorname{Pr}\left[y_{2 j}=1\right]$ are now two-dimensional, such that in each market we now have a bi-variate choice probability model discribing the two choice situations $D_{j}$ for $j=1,2$ as :

$$
\begin{aligned}
& \operatorname{Pr}\left[y_{1 j}=1\right]=F\left(X_{j}^{\prime} \beta_{1 j}\right)=\Phi\left(X_{j}^{\prime} \beta_{1 j}\right) \quad \text { For the Health Care Market } \\
& \operatorname{Pr}\left[y_{2 j}=1\right]=F\left(X_{j}^{\prime} \beta_{2 j}\right)=\Phi\left(X_{j}^{\prime} \beta_{2 j}\right) \quad \text { For the Labor Market }
\end{aligned}
$$

\section{Econometric Specification and Model Identification}

In this section we present two types of Econometric specifications. One corresponding to the recursive trivariate probit specification (RTPS), obtained from the trivariate sample selection model (TSSM) 3.1, and the other corresponding to the recursive bivariate probit specification (RBPS), obtained from the bivariate sample selection model (BSSM) 3.2. 


\subsection{Recursive Trivariate Probit Specification (RTPS)}

The RTPS of co-residence, health care market, and labor market outcomes is built for all $i=1,2$, with ( $i=1$ if health care market; $i=2$ if labor market) as shown in equation 6 as follows: the selection process or co-residence decision (Coresid):

$$
\text { Coresid }= \begin{cases}1 & \text { if }\left(U_{i 01}-U_{i 00}\right)>0 \text { or } \tilde{U}_{i 0}>0 \\ 0 & \text { if }\left(U_{i 01}-U_{i 00}\right) \leq 0 \text { or } \tilde{U}_{i 0} \leq 0\end{cases}
$$

the participation process or extensive margin (EM):

$$
E M= \begin{cases}1 & \text { if }\left(U_{i 11}-U_{i 10}\right)>0 \text { or } \tilde{U}_{i 1}>0 \\ 0 & \text { if }\left(U_{i 11}-U_{i 10}\right) \leq 0 \text { or } \tilde{U}_{i 1} \leq 0\end{cases}
$$

and the level of participation or intensive margin (IM):

$$
I M= \begin{cases}1 & \text { if }\left(U_{i 21}-U_{i 20}\right)>0 \text { or } \tilde{U}_{i 2}>0 \\ 0 & \text { if }\left(U_{i 21}-U_{i 20}\right) \leq 0 \text { or } \tilde{U}_{i 2} \leq 0\end{cases}
$$

The recursive trivariate system of additive random utilities is obtained as:

$$
\left\{\begin{array}{l}
\tilde{U}_{i 0}=X_{0} \beta_{i 0}+\tilde{\epsilon}_{i 0} \\
\tilde{U}_{i 1}=\beta_{01} \text { Coresid }+X_{1} \beta_{i 1}+\tilde{\epsilon}_{i 1} \\
\tilde{U}_{i 2}=\beta_{02} \text { Coresid }+\beta_{12} E M+X_{2} \beta_{i 2}+\tilde{\epsilon}_{i 2}
\end{array}\right.
$$

Where $\tilde{U}_{i 0}$ represent the differences in utility associated with inter-generational co-residence, $\tilde{U}_{i 1}$ the differences in utility associated with participation (Extensive Margin); while $\tilde{U}_{i 2}$ represent the differences associated with intensive participation (Intensive Margin). For all $i=1,2$ independents, and $j=0,1,2$ dependents, equation 11 can be rewritten more succinctly as:

$$
\tilde{U}_{i j}=X_{j} \beta_{i j}+\tilde{\epsilon}_{i j}
$$

where $\tilde{U}_{i j}$ is a vector of utility differences, $X_{j}$ is the design matrix in the $j^{\text {th }}$ choice situation, representing the explanatory variables in the system, and $\tilde{\epsilon}_{i j}$ the vector of random disturbances. This general multivariate probit specification in equation (12) with the latent utility differences $\tilde{U}_{i j}$ follow the trivariate normal distribution for all $i=1,2$ :

$$
\left(\begin{array}{c}
\tilde{U}_{i 0} \\
\tilde{U}_{i 1} \\
\tilde{U}_{i 2}
\end{array}\right) \sim N_{3}\left[\left(\begin{array}{c}
\tilde{\mu}_{i 0} \\
\tilde{\mu}_{i 1} \\
\tilde{\mu}_{i 2}
\end{array}\right),\left(\begin{array}{ccc}
\tilde{\sigma}_{i 0} & \tilde{\theta}_{i 01} & \tilde{\theta}_{i 02} \\
& \tilde{\sigma}_{i 1} & \tilde{\theta}_{i 12} \\
& & \tilde{\sigma}_{i 2}
\end{array}\right)\right]
$$


where $\tilde{\mu}_{i j}$ and $\tilde{\sigma}_{i j}$ are respectively the mean and variance for $\tilde{U}_{i j}$, while the $\tilde{\theta}_{i j k}$ are scalar correlation parameters.

In this formulation, each triplet of decision outcomes $\left(Y_{i j 0}, Y_{i j 1}, Y_{i j 2}\right)$ has $2 \times 2 \times 2=8$ potential outcomes, $\left(Y_{i j 0}=1, Y_{i j 1}=1, Y_{i j 2}=1\right),\left(Y_{i j 0}=1, Y_{i j 1}=1, Y_{i j 2}=0\right)$, and $\left(Y_{i j 0}=1, Y_{i j 1}=\right.$ $\left.0, Y_{i j 2}=1\right)$, and $\left(Y_{i j 0}=0, Y_{i j 1}=1, Y_{i j 2}=1\right)$, and $\left(Y_{i j 0}=0, Y_{i j 1}=1, Y_{i j 2}=0\right)$, and $\left(Y_{i j 0}=\right.$ $\left.0, Y_{i j 1}=0, Y_{i j 2}=1\right)$, and $\left(Y_{i j 0}=1, Y_{i j 1}=0, Y_{i j 2}=0\right),\left(Y_{i j 0}=0 Y_{i j 1}=0, Y_{i j 2}=0\right)$. The joint probability for these eight outcomes is modeled with six systematic components: the marginal probabilities $\operatorname{Pr}\left(Y_{i j 0}=1\right), \operatorname{Pr}\left(Y_{i j 1}=1\right)$, and $\operatorname{Pr}\left(Y_{i j 2}=1\right)$ and the correlation parameters $\tilde{\theta}_{i 01}$, $\tilde{\theta}_{i 02}$, and $\tilde{\theta}_{i 12}$ for the three marginal distributions. For identification purposes, we restrict the diagonal elements (variances) $\tilde{\sigma}_{i j}$, for $j=0,1,2$ and $i=1,2$ in equation(13) to 1 . Since the correlation parameters do not correspond to one of the decision outcomes, the model estimates $\tilde{\theta}_{01}, \tilde{\theta}_{02}$, and $\tilde{\theta}_{12}$ as constants by default, in each market. Hence, only the three means equations $\left(\tilde{\mu}_{i 0}\right.$ or the average difference in utility associated with co-residence (selection); $\tilde{\mu}_{i 1}$ or the average difference in utility associated with participation (extensive margin); $\tilde{\mu}_{i 2}$ the average difference in utility associated with intensive participation (intensive margin) ) are required. Each of these systematic components are modeled as functions of sets of explanatory variables. Identification of the above described parameters for the recursive trivariate probit specification is achieved using penalized maximum likelihood methods as described in Wojtys et al. (2016).

\subsection{Recursive Bivariate Probit Specification (RBPS)}

Since the recursive bivariate probit specification (RBPS) is obtained from the bivariate sample selection model (BSSM) as shown in section3.2, through a one dimensional restriction on the TSSM in section3.1, its specification is easily derived for all $i=1,2$ independents, from equation 11 as:

$$
\left\{\begin{array}{l}
\tilde{U}_{i 1}=\beta_{01} \text { Coresid }+X_{1} \beta_{i 1}+\tilde{\epsilon}_{i 1} \\
\tilde{U}_{i 2}=\beta_{02} \text { Coresid }+\beta_{12} E M+X_{2} \beta_{i 2}+\tilde{\epsilon}_{i 2}
\end{array}\right.
$$

or more compactly for all $i=1,2$ and $j=1,2$ as:

$$
\tilde{U}_{i j}=X_{j} \beta_{i j}+\tilde{\epsilon}_{i j}
$$

Parameters estimation for the bivariate utility function in equation 15 by maximum likelihood is straightforward if we make the following assumption about the correlated errors for all $i=1,2$ :

$$
\left(\begin{array}{c}
\tilde{\epsilon}_{i 1} \\
\tilde{\epsilon}_{i 2}
\end{array}\right) \sim F_{i 2}\left[\left(\begin{array}{l}
0 \\
0
\end{array}\right),\left(\begin{array}{cc}
1 & \tilde{\sigma}_{i 12} \\
& \tilde{\sigma}_{i 2}^{2}
\end{array}\right)\right]
$$

Where the normalization $\tilde{\sigma}_{i 1}^{2}=1$ is used for identification purposes. Heckman two step estimator Heckman, 1979) can be used to identify this bivariate system, see (Cameron and Trivedi, 
2005, 547-548). In our analysis, both the bi-variate probit and trivariate probit are implemented in the R Statistical Software (R Core Team, 2015), using the library Marra and Radice (2017).

\section{Data}

As previously mentioned in the introduction, the data used in this analysis is a pooled cross section of the 2015-2016 National Health Interview surveys (NHIS) (National Center for Health Statistics and others, 2015, 2016). First initiated in 1957 by the National Health Survey Act of 1956, the NHIS has been conducted since 1960 by the National Center for Health Statistics (NCHS) (Blackwell et al., 2014). Although redesigned after every decennial census, NHIS is a cross-sectional household, multistage probability sample survey conducted annually by interviewers of the U.S. Census Bureau for the Centers for Disease Control and Prevention's National Center for Health Statistics. Further details on the current sampling design is found in the NCHS report (Parsons et al., 2014). The target population is the civilian non-institutionalized population residing in the United States at the time of the interview.

The sample size can vary from year to year based on budgetary constraints. The normal annual sample size (i.e., the number of households and/or persons from whom data are collected and publicly released) for the prior 2015 sample design, and the new 2016 sample design is about 35,000 households containing about 87,500 persons. In 2014, the sample size was augmented by approximately $27 \%$; in 2015 , by approximately $19 \%$; and in 2016 , by approximately $15 \%$ (National Center for Health Statistics and others, 2016). Each annual NHIS questionnaire (also called the Core) consists of four main components: Household Composition Section, Family Core, Sample Adult Core, and Sample Child Core. The data used in the current analysis is from the sample adult core, which obtains additional information on health conditions, activity limitations, health behaviors, and access to and use of health care services from one randomly selected adult (the "sample adult") in the family.

The publicly released data files (also called "public use data files") for the 2015 NHIS contain data for 41,493 households containing 103,789 persons in 42,288 families, while the 2016 data concerns 40,220 households containing 97,169 persons in 40,875 families. The conditional response rate for the 2015 sample adult component is $79.7 \%$, which is calculated by dividing the number of completed sample adult interviews $(33,672)$ by the total number of eligible sample adults $(42,270)$. The unconditional or final response rate of $55.2 \%$ is calculated by multiplying the conditional rate of $79.7 \%$ by the final family response rate $69.3 \%$ (National Center for Health Statistics and others, 2015). Similarly, the conditional response rate for the Sample 2016 adult component is 80.9\%, which is calculated by dividing the number of completed sample adult interviews $(33,028)$ by the total number of eligible sample adults $(40,848)$, while the unconditional or final response rate of $54.3 \%$ is calculated by multiplying the conditional rate of $80.9 \%$ by the final family response rate 67.1\% (National Center for Health Statistics and others, 2016). After variables selection, data 
treatment, and accounting for missing information, the pooled cross-sectional panel data used in the final analysis contains a total of 32397 observations, 16028 of which are from the 2015 sample adult component and the remaining 16369 from the 2016 sample adult component. Below is the description of the selected variables for our analysis.

\subsection{Access to Health care}

Individual's access to health care is measured as a binary indicator (PNMED12M) In the NHIS data. It is the outcome of the question : "During the past 12 months, was there any time when the individual needed medical care, but did not get it because the individual couldn't afford it?" as such, PNMED12M takes the value 1 if yes, and 2 if No. For our analysis, we create the binary variable "Access" which takes the value 0 if PNMED12M $=1$, and the value 1 if PNMED12M $=2$. This variable "Access" is intended to describe the "extensive margin" of health care demand in our analysis.

\subsection{Utilization of Health care}

Individual's utilization of health care is also measured as a binary indicator (P10DVYR) In the NHIS data. It is the outcome of the question : "During the past 12 months, did the person receive care from doctors or other health care professionals 10 or more times? Does not include telephone calls". Therefore the variable P10DVYR takes the value 1 if yes and 2 if No. For our analysis, we create the binary variable "Utilization" which takes the value 0 if P10DVYR $=1$, and the value 1 if $\mathrm{P} 10 \mathrm{DVYR}=2$. This variable "Utilization" is intended to capture the "Intensive margin" of health care demand in our analysis.

\subsection{Level of Health care Expenditure}

The family's level of health expenditure is measured as a nominal variables with six modalities (HCSPFYR) in the NHIS data. It is the outcome of the question: "The next question is about money that [you have/your family has] spent out of pocket on medical care. We do not want you to count health insurance premiums, over the counter drugs, or costs that you will be reimbursed for. In the past 12 months, about how much did [you/your family] spend for medical care and dental care?". As such the variable HCSPFYR $=0$ if amount spent is zero, HCSPFYR $=1$ if less than $\$ 500$, HCSPFYR $=2$ if $[\$ 500 ; \$ 1,999]$, HCSPFYR $=3$ if $[\$ 2,000 ; \$ 2,999]$, HCSPFYR $=4$ if $[\$ 3,000 ; \$ 4,999]$, and HCSPFYR $=5$ if $\$ 5,000$ or more. For our analysis, we create the variable "FamMedExp" which combines the modalities 3, 4 and 5 of HCSPFYR into a single category, such that "FamMedExp" is also multinomial with 4 modalities represented as: FamMedExp = 0 if HCSPFYR $=0$, FamMedExp $=1$ if HCSPFYR $=1$, FamMedExp $=2$ if HCSPFYR $=2$, FamMedExp $=3$ if HCSPFYR $=3$, FamMedExp $=4$ if HCSPFYR $=4$ or more. This variable "FamMedExp" is intended to capture the "Out-of-pocket" non reimbursed cost of health care demand in our analysis. 


\subsection{Labor Supply}

Individual's labor supply is measured by employment status and weekly hours of work. Employment status is a multinational variable with 5 modalities and captured by (DOINGLWP) in the NHIS; It is the outcome of the question: "Which of the following was the individual doing LAST WEEK?". On the other hand, weekly hours of work is a non-negative continuous variable and represented by (WRKHRS2) in NHIS; it is the outcome of the question: "How many hours did the individual work last week at all jobs or businesses?" or "How many hours does the individual usually work weekly at all jobs or businesses?".

The different modalities of employment status are DOINGLWP $=1$ if working for pay at a job or business; DOINGLWP $=2$ if with a job or business but not at work; DOINGLWP $=3$ if looking for work; DOINGLWP $=4$ if working, but not for pay, at a family-owned job or business; DOINGLWP $=5$ if not working at a job or business and not looking for work. For our analysis we use this variable to create the binary variable "WorkStat", as the individual's employment status which takes the values WorkStat $=1$ if DOINGLWP $=1$ (or working for pay at a job or business), and WorkStat $=0$ otherwise. This variable "WorkStat" is used to describe the "extensive margin" of individual's labor supply. For the "intensive margin" of labor supply we use the binary variable "Full-time" to describe whether or not an individual is working part-time (WRKHRS2 less than 40 hours a week) or full-time (WRKHRS2 greater than or equal to 40 hours a week).

\subsection{Inter-generational Co-residence}

To obtain the main independent variable describing individual's inter-generational co-residence status, we use the variable (PARENTS) in the NHIS. This variable is multinational with 4 levels, and is the outcome of the question: "Which of your Parent(s) is(are) present in the family ?"; therefore the 4 modalities of the variable are: PARENTS $=1$ if mother, no father ; PARENTS $=$ 2 if father, no mother ; PARENTS $=3$ if mother and father ; and PARENTS $=4$ if neither mother nor father. For our analysis the Inter-generational co-residence status is captured by the binary indicator variable "Coresid" which takes the values Coresid $=0$ if PARENTS $=4$; and Coresid $=1$ if $($ PARENTS $=1$, or 2 , or 3$)$. The interpretation of this variable is that an individual is in inter-generational co-residence if he/she lives in the same household with at least one of his parents $($ coresid $=1)$, and conversely (coresid=0) if neither mother nor father lives in the household. Here mother and father can include biological, adoptive, step, and foster relationships, but not legal guardians.

Although earlier authors have considered inter-generational co-residence as exogenous, for example in the case of US female labor market outcomes (Kolodinsky and Shirey, 2000), numerous authors have since shown it's potential endogeneity, and the bias involved with treating it as an exogenous factor (Emran et al., 2015; Shahe Emran et al., 2016; Emran and Shilpi, 2017). 
One potential source of endogeneity is unobserved characteristics such as family values, relating both to individual's co-residence decisions and labor market outcomes. For example, individuals' who highly value family ties are inclined to co-reside with their parents, and also to spend more time in domestic work but less time in market work (Díaz and Dolores, 2005). As a result, unobserved characteristics introduce a downward bias in the relationship between co-residence and individuals' labor supply. Another source of endogeneity is reversed causality. Since market alternatives to services provided by co-residing parents such as childcare (Gorry and Thomas, 2017; Brady, 2018) and housekeeping (Romero, 2002; Coltrane, 2000) can be very expensive in the US(Kimmel, 1998), married individuals who want to work are more likely to reside with their parents in order to benefit from these services as parents share the burden of household work (Lilly et al., 2007; Zamarro, 2011). In such a case, the estimated impact of co-residence on individual employment is biased upwards if co-residence is assumed exogenous.

To solve this endogeneity problem, authors have mainly relied on Instrumental variable (IV) methods (Compton and Pollak, 2014) in the USA, (Sasaki, 2002; Oshio, 2006) in japan, (MaurerFazio et al., 2011; Shen et al., 2016) in China, and (Landmann et al., 2017) in Kyrgyzstan. The current analysis departs from this trend by relying instead on endogenous switching methods(Lee and Porter, 1984) implemented through the recursive trivariate probit specification as described in section 4.1. We then proceed to test the significance of the correlation coefficients produced by the model. If they are significant, then there is indeed presence of endogeneity, and the recursive trivariate probit model will be more appropriate. If instead the correlation coefficients are not significant, then co-residence would be exogenous, in which case the bivariate recursive model as described in section 4.2 will suffice to represent the effects of inter-generational co-residence on health care market and labor market outcomes.

\subsection{Control variables: Co-variates}

Like any scientific study using evidence from observational data, our interests here centers on a postulated causal influence from the attributes and environment of individuals' to their responses, or observed health care market and labor market choices. As highlighted in the above discussion, it's assumed that the observed health care market and labor market choices reflect individuals' inter-generational co-residence status, as influenced by the socio-political and contextual framework conditioned by the ACA. As such, in choosing the variables to be included in the models, the question that needs to be addressed in conjunction with our proposed behavioral model is: what other factors affect individuals' health care market and labor market behaviors in the USA ?

Keeping in mind that the primary goal of this empirical analysis is not to describe the determinants of individuals' health care market and labor market choices in the USA, but to evidence the role that inter-generational co-residence play in affecting individuals' health care market and labor market choices in post-ACA USA, then our main independent variable of interest is individuals' inter-generational co-residence status. In order however to achieve the study goal, we need to 
also control for the effects of other co-variates impacting these relationships. Table (1) provides definitions and summary statistics for all the variables used in the analysis.

\section{Results and Discussions}

Focusing on the unconditional distribution of the variables as described in table (1), we note that the mean time spent working per week in the pooled sample is 41.4 hours, with the men sub-sample average relatively higher at 43.88 hours than the women sub-sample average of 38.85 hours. This average working time was 42.62 hours and 41.20 hours in 2015, and 2016 respectively. Similarly, the mean age in the pooled sample is 44.42 years, and is fairly stable across sex, and year. Finally, looking at insurance premium, the pooled sample average premium cost is found to be $\$ 3951$, distributed across sex at $\$ 4107$ for men, and $\$ 3790$ for women, and across time at $\$ 3876$ in 2015 and $\$ 4024$ in 2016.

With regards to our variables of direct interest, in the pooled sample $8.5 \%$ of the respondents reported co-residing with at least one parent, against $91.5 \%$ who reported not. This distribution is fairly similar for the women and men sub-samples alike, and independently of time. Turning our attention to the extensive margins, the pooled sample results show in the health care market that $96.8 \%$ of the respondents had no problem accessing care, while in the labor market $95.7 \%$ reported working for pay during the 2 weeks prior to the survey. Moving to the intensive margins, the pooled sample shows in the health care market that only $8.7 \%$ had used intensively (10 times or more) health care, while in the labor market $78.4 \%$ reported working full-time (more than 40 hours a week). With regards to resource expenditure in the process of participation in the health care market, $33.1 \%$ of the respondents reported having medical expenses below $\$ 500,35.1 \%$ reported spending between $\$ 500$ to $\$ 2,000$, while the remaining $31.8 \%$ reported expenditure above $\$ 2000$. In the labor market however, where resource expenditure is measured in terms of hours spent working, the pooled sample results in the last column of table (1) suggest that $21.6 \%$ of respondents worked part-time (40 hours or less per week), 77.3\% worked between 40-80 hours, while only $1.1 \%$ worked over 80 hours. As a major determinant of inter-generational co-residence, annual earnings figures in table (1) suggests that $33.8 \%$ of the respondent have annual earnings below $\$ 35,000,35.2 \%$ have earnings between $\$ 35,000$ and $\$ 65,000$, while the remaining $30.7 \%$ have earnings above $\$ 65,000$. The remaining summary statistics for the other co-variates are provided in table (1), which presents the means and standard deviations for the continuous variables, while relative frequency distributions are shown for the nominal variables.

In addition to the above presented unconditional distribution results, we also describe the association between variables using cross-tabulations and chi-square tests. We test not only the link between our primary variable of interest (Inter-generational co-residence) and a set of nominal explanatory variables, but also its link with health care market outcome indicators (access, usage, and levels of out-of-pocket spending in dollar), and labor market outcome indicators (work status, 
full-time status, and levels of hours spent working). The results for these tests are presented in table(2). Except for work status, all market outcome indicators show a p-value less than the $5 \%$ significance level, suggesting their dependence with inter-generational co-residence at a $95 \%$ confidence level.

Table(2) also presents conditional frequency distributions of co-residence with the outcomes in the health care market and labor market, for the men and women sub-samples, and the pooled sample respectively. Focusing on the women sub-sample results, we note that among the women co-residing with at least one parent, the greater share $(97.5 \%)$ reports not having any problem accessing care, while only $2.5 \%$ reports having difficulties. With regards to health care usage during the same year, among co-residing women, $5.9 \%$ reports using health care services 10 times or more during the year, against $94.1 \%$ who reports less usage. For medical health expenditure levels, among co-residing women, $27.7 \%$ show spending level below $\$ 500,35.6 \%$ spend between $\$ 500$ and $\$ 2,000$, while the remaining $30.2 \%$ have expenditure above $\$ 2000$.

With respect to labor market outcomes, among co-residing women, at the extensive margin 95.6\% reports working for pay, while only $4.1 \%$ reports not working. At the intensive margin, in the binary scale $45.5 \%$ reports working part-time (less than 40 hours a week), against 54.5\% who reports working full-time (more than 40 hours). On the multinational scale of intensive labor supply, $54.1 \%$ of co-residing women reports working between $40-80$ hours a week, while only $0.4 \%$ works over 80 hours a week. The conditional distributions of co-residence with the health care market and labor market outcomes, for the men sub-sample and the pooled sample are fairly similar to that just described for the women sub-sample as shown in table (2). For the sake of keeping the discussion concise, the reader is directed towards table (2) for the remaining details on the conditional distribution of co-residence with the other co-variates.

Now focusing our attention on our variables of interest, and abstracting from the estimated control variables (co-variates) effects in the estimated models, table (3) gives the summary representation of the effects of inter-generational co-residence on health care market and labor market outcomes during 2015-2016. To arrive at these results, our analytical strategy consisted of three model estimations in each market as presented below.

In the health care market, we look at the effects of co-residence on access to health care ( the extensive margin), usage of health care (the intensive margin) and expenditure on health care, using the women sub-sample, the men sub-sample and the pooled sample. The analytical strategy in the labor market is similar to that adopted in the health care market, allowing us to estimate the effects of co-residence on labor market outcomes, based on the men and women sub-samples and also the pooled sample.

Although we control for the effects of a great number of co-variates in each market, the presented and discussed results will focus mainly on our primary effects of interests. Furthermore, since the effect of co-residence on labor market outcomes (labor supply) has received much more attention in the literature, especially the case of female labor supply, than its effects on health care market 
outcomes, we will keep the labor market discussions brief, while providing a much detailed account of the health care market results, which to the best of our knowledge has been fairly untouched in the period post- ACA enforcement.

\subsection{The Selection Process}

The selection process describes the determining factors in inter-generational co-residence decisions in post-ACA USA. The estimated results of this process are shown in table (3) for the men and women sub-samples, and also the overall pooled cross-sectional sample. Here, co-residence is estimated jointly with the extensive margin, and the intensive margin in both the health care market, and the labor market.

In table (3) under each market, the first column presents the results of the female sub-sample, the second column the results of the male sub-sample, and the third column the results of the pooled cross-sectional sample. We note that the effects of the factors affecting co-residence in the USA are fairly robust across gender and market, based on the signs and significance. Factors such as earnings, age, US citizenship and education have negative affects on men and women coresidence decisions. In fact, compared to females earning less than $\$ 35,000$, those earning between $\$ 35,000$ and $\$ 65,000$ are $40.6 \%$ (in the health care market) and $35.6 \%$ (in the labor market) less likely to co-reside with a least one parent, while those earning above $\$ 65,000$ are $42.6 \%$ (in the health care market) and $35.2 \%$ (in the labor market) less likely to co-reside with at least one parent. The age coefficient suggests also that every one year increase in the age of a female respondent reduces her likelihood of co-residing with parents by $4 \%$ (in the health care market) and $4.1 \%$ (in the labor market). Similarly, every one level increase in education reduces females' likelihood of co-residing with parents by $4.4 \%$ (in the health care market) and $5.2 \%$ (in the labor market). Furthermore, based on US citizenship status, compared to their US citizen counterparts, female non-citizens are found to be $42 \%$ (in the health care market) and $37.1 \%$ (in the labor market) less likely to co-reside with parents.

With respect to race, the results suggest that compared to white females, only Asian female respondents show a significant and positive difference in likelihood of co-residence with parents. In fact, they have $33.3 \%$ (in the health care market) and $33.7 \%$ (in the labor market) more chances of co-residing with parents. Looking at the effects of marital status, we see that compared to currently married female respondents, previously married females are $61.9 \%$ ( in the health care market) and $57.8 \%$ (in the labor market) more likely to co-reside with at least one parent. Similarly for never married females compared to those currently married who are $89.3 \%$ ( in the health care market) and $82.6 \%$ (in the labor market) more likely to co-reside with parents.

Similar findings are also observed with the regional Dummies, where compared to females living in the south, those in the northwest and west are more likely to co-reside with at least one parent, while those in the Midwest are relatively less likely. More specifically, the relative likelihood of co-residence for females in the northwest compared to those in the south is $21.9 \%$ ( in the health 
care market) and $19.7 \%$ (in the labor market). In the west, this relative likelihood of co-residence over the southern females is $8.7 \%$ ( in the health care market) and $7.3 \%$ (in the labor market). In the Midwest however the relative unlikelihood of co-residence over the southern females is $16.4 \%$ ( in the health care market) and $15.3 \%$ (in the labor market). The place of birth seems to also matter significantly in co-residence decisions, with females born outside of the US found to be 35.3 $\%$ ( in the health care market) and $28.9 \%$ (in the labor market) more likely to co-reside compared to those born in the USA.

The males' results suggest relatively similar effects in terms of signs and significance as those above described for the females sub-sample. The distinction with the males comes from the regional differences in co-residence, with no significant relative difference in the Northwest and the west compared to southern males. Finally, focusing on the pooled cross-sectional sample results as shown in column (3) under each market, we note that the estimated coefficient values for all the factors explaining inter-generational co-residence in the US between 2015 and 2016 are fairly stable and robust across markets. We also note that all variables retain their signs and significances as in the females and males sub-samples; the only added difference is the effect of sex, which suggests that compared to men, women are $7.6 \%$ (in the health care market) and $8.5 \%$ (in the labor market) less likely to co-reside with parents. This latter result seems to indicate that the process leading to female co-residence in the USA, significantly differs from that leading to male co-residence.

\subsection{Co-residence Effects on Health Care Market Outcomes}

The effects of inter-generational co-residence on health care market outcomes in the US is presented on the upper panel of table (4) for the males sub-sample, the females sub-sample and the pooled sample. Focusing on its effect on the extensive margin of the health care market, we see that co-residing with at least one parent consistently improves the likelihood of accessing health care in the US. In fact, among female respondents, those co-residing with at least one parent are 1.17 times more likely to access health care. This figure among male respondents shows an improvement in access to health care by a factor of 1.21 for those co-residing, compared to their non-co-residing counterparts. Abstracting from gender differences, co-residence still impacts positively access to care by a factor of 1.22 in the USA.

Looking at its effect on the intensive margin of health care, we note that only in the females sub-sample and the pooled sample is co-residence affecting significantly intensive usage (10 times or more annually) of health care. In fact, among female respondents, co-residence with at least one parent reduces the intensive use of health care by $57.1 \%$. Similarly, its overall effect in the pooled sample suggest that inter-generational co-residence reduces by $31 \%$ individuals' intensive usage of health care in the US. In terms of resource expenditure in the process of health care access and usage, we note that irrespective of gender inter-generational co-residence increases significantly health care expenditure in the US. In fact, among females, co-residence increases health care 
expenditure by $56.7 \%$, while this figure increases to $74.2 \%$ among males. Overall however, and abstracting from gender differences, co-residence increases individuals' expenditure by $69.7 \%$.

Moving to the estimated values of the correlation coefficients $\left(\theta_{01}, \theta_{02}, \theta_{12}\right)$ between the health care market outcome indicators as represented in equation 13, the results in the upper panel of table (4) suggest that $\theta_{01}$ the correlation coefficient between the selection process (Co-residence) and the extensive margin (Access) although not significant for the males sub-sample is negative and significant for both the females sub-sample and the pooled sample. In fact, the females sub-sample correlation coefficient is $-39.6 \%$ with $95 \%$ confidence interval $[-62.1 \% ;-18.4 \%$ ], while the pooled sample correlation coefficient is $-34.6 \%$ with corresponding $95 \%$ confidence Interval of $[-55.9 \% ;-10.9 \%]$. These results further suggest that the unobserved factors affecting individual respondents decisions to co-reside with at least one parent correlate negatively with those affecting their likelihood of accessing health care in the US, and even more so for females. Conversely, the correlation coefficient $\theta_{12}$ between the extensive margin (Access) and the intensive margin(Usage) is consistently positive and significant across all sub-samples as shown by the coefficient values $45 \%$ (among females), 23.6\%(among males) and 37.8\% (in the pooled sample) and their 95\% confidence intervals, which are void of zero. These later results suggest that the unobserved factors affecting individuals' access to health care despite costs in the US, correlate positively with those affecting their intensive usage of health care (10 times or more) during a year. Conversely, since $\theta_{02}$ is consistently not significant as shown by the $95 \%$ confidence intervals which contain zero, we can safely conclude that the unobserved factors affecting respondents' decision to co-reside with parents are unrelated to those affecting their intensive use of health care in the US between 2015-2016.

\subsection{Co-residence Effects on Labor Market Outcomes}

The effects of inter-generational co-residence on labor market outcomes in the US is presented on the lower panel of table (4) for the males sub-sample, the females sub-sample and the pooled sample. Focusing on its effect on the extensive margin of the labor market as shown in the first column of the table under "Work Status", we note that co-residence with at least one parent significantly affects work status only in the females sub-sample. More specifically it reduces the likelihood of females participation in the US labor market by $45 \%$ during 2015 and 2016.

Looking at its effect on the intensive margin of the labor market as shown in the second column of the lower panel, we find that co-residence unilaterally reduces the likelihood of working full-time (more than 40 hours per week), in all the considered sub-samples. This effect varies across sex in the range of $[-1.575 ;-1.552]$. In terms of resource expenditure in the process of participating in the labor market, the results shown in the third column of the lower panel of table (4) suggest also that inter-generational co-residence reduces significantly the number of hours supplied in the US labor market. This effect is significant at the $0.1 \%$ level and varies in the range of $[41 \% ; 55.6 \%]$ across sex and suggests that on average in 2015-2016, compared to individuals not co-residing with 
parents, those co-residing with at least one parent work about $55.4 \%$ fewer hours in the US labor market.

Moving to the estimated values for the correlation coefficients $\left(\theta_{01}, \theta_{02}, \theta_{12}\right)$ between labor market outcomes as represented in equation 13, the results are presented in column (4), (5), and (6) of the lower panel of table (4). These results show that $\theta_{01}$ the correlation coefficient between the selection process (Co-residence) and the extensive margin (Work Status) is not significant as shown by the $95 \%$ confidence intervals that do contain zero. These results further suggest that the unobserved factors affecting individual respondents' decisions to co-reside with parents are unrelated to those affecting their likelihood of participating in the US labor market between 2015-2016. Conversely however, $\theta_{02}$ is consistently positive and statistically significant as shown by the $95 \%$ confidence intervals which are void of zero, therefore we can say that the unobserved factors affecting respondents' decision to co-reside with parents correlate positively at $61.1 \%$ with those affecting their intensive participation (more than 40 hours) in the US labor market between 2015-2016.

Finally the results for $\theta_{12}$, the correlation coefficient between the extensive margin (Work Status) and the intensive margin(Full-time) is also positive and significant for the females sub-sample and the pooled sample, as shown by their $95 \%$ confidence intervals, which are both void of zero. These later results suggest that although not significant for men, the unobserved factors affecting affecting women labor market participation in the US during 2015-2016 correlate positively at $7.7 \%$ with the unobserved factors affecting their intensive participation (more than 40 hours per week) in the US labor market. This correlation independently of sex, using the pooled sample is statistically significant at $4.8 \%$.

\subsection{Co-variates' results in the Labor Market and Health Care Market}

In the labor market, we find that in addition to inter-generational co-residence, co-variates such as annual earnings, physical health status, intensive usage of health care during the year, marital status, age and education all impact significantly labor market outcomes ( Extensive margin, intensive margin, and resource expenditure), for both men and women, and overall. These results corroborate with those of previous authors that looked at inter-generational co-residence on labor supply, especially the case of female labor supply which has received relatively more attention in the literature over the years: Shen et al. (2016) in china, Landmann et al. (2017) in Kyrgyzstan, and in the USA Kolodinsky and Shirey (2000); Compton and Pollak (2014).

The case of inter-generational co-residence and health care market outcomes however is yet to receive the same level of attention in the literature, therefore in addition to the above discussed effects of co-residence, we will provide a much detailed account of the effects of the co-variates on our health care market outcomes of "Access", "Usage" and "Expenditure".

Starting with the extensive margin in the health care market, in terms of females access to health care, we find that increased earnings level raises females' likelihood of accessing health care. 
More specifically, compared to females earning less than $\$ 35,000$ those earning annually between $\$ 35,000$ and $\$ 65,000$ are respectively $27.37 \%$ and $43.21 \%$ more likely to access the health care market. Similarly, the women reporting having no problem paying medical bills are found to be 97.47\% more likely to access health care compared to those who report having problems. Also, the women that report not having any medical bills to pay over time, compared to those who do have, are $23.69 \%$ more likely to access health care. The results of females access to health care suggest however no significant differences in females' access to health care based on race, region of residence, place of birth, or citizenship between 2015-2016. This later result seems to suggest that ACA by reorganizing the US health care market, has succeeded in reducing significantly health care access disparities among females based on race, region of residence, place of birth, citizenship in the country. However, the results do support a significant marital status effect, with currently married females having respectively $55.77 \%$, and $48.33 \%$ more chances of accessing health care, compared to their previously married, and never married counterparts in the US. Similarly, every one year increase in females' age leads to a $0.5 \%$ increase in likelihood of access to care in the US between 2015-2016.

Moving to the intensive margin in the health care market, in terms of females' annual usage of health care services between 2015 -2016, the results suggest that reported physical health deterioration for females increases their likelihood of using health care intensively (10 times or more) during the year. Similarly, in relation to regional differences in females intensive use of health care between 2015-2016, only females in the northwest show a significantly positive difference in intensive health care usage compared to those in the south. Also, in relation to marital status, compared to the currently married females, those that were previously married are found to be $11.75 \%$ more likely to use health care intensively. Education is also found to contribute positively to females' annual intensive health care usage at a rate of $5.15 \%$ for every one level increase in education between 2015-2016.

The coefficient values on the race control dummies, suggest that compared to white females, females from all other races (black, Asian, and others) are less likely to use health care 10 times or more annually; however, this effect is only significant in the case of black females, and show that this later group is $17.69 \%$ less likely to use health care intensively during the year, than their white females counterparts. In addition the females that reported having no difficulty accessing the health care market because of costs, are found to have 1.28 times less chances of using health care intensively during the year. This later result although seemingly counter-intuitive may be explained by the fact that those females with easy access to health care are more able to use the right amount of preventive care, allowing them to avoid unnecessary health care consumption during the year, from ill health. Similar observation is made about the women that reported not having a flexible spending account (FSA), which are found to be $23.21 \%$ less likely to use health care intensively during the year, compared to those women with FSA. Also, those females that reported not being limited in anyway (physical, mental, or emotional) are found to be $80.40 \%$ 
less likely to use health care intensively during the year, compared to those that reported being limited. In addition, compared to the females with single service plans, those with multiple service plans are found to be $11.24 \%$ less likely to use health care services 10 times or more during the year. Furthermore, age is also found to reduce significantly females' likelihood of intensive health care usage by $0.65 \%$ for each additional year of age. Based on the place of birth, compared to the females born outside of the US, those born inside are $21.02 \%$ less likely to use health care intensively, although no significant difference is found on the ground of female citizenship status.

Overall, after accounting for the effects of the above mentioned co-variates, the dependence among the three processes of co-residence with parents, accessing health care, and using health care intensively, for women in the USA between 2015-2016, we found that indeed the unobserved factors affecting females' decisions to co-reside with parents correlate negatively at 39.6\% (-62.1\%, $18.4 \%$ ) with those affecting their likelihood of accessing health care, and unrelated to those affecting their likelihood of intensive health care usage. However, the dependence between access to, and intensive usage of health care is significantly positive at $45.1 \%(31.3 \%, 54.7 \%)$. These correlation results suggest indeed the presence of endogeneity in the effects of inter-generational co-residence on health care market, and labor market outcomes. And furthermore that the recursive trivariate probit model specification described in section (4.1) is more appropriate for describing the effect of co-residence on healthcare market, and labor market outcomes. In fact, by explicitly modeling the co-residence process using a binary equation, and allowing correlations between the error term of this process with those produced by the extensive margin and intensive margin equations respectively, we are able to accommodate for the bias that would have otherwise prevailed have we assumed co-residence exogeneity, and relied on the recursive bi-variate probit model described in section (4.2).

Detailed descriptions of the males sub-sample, and the pooled sample results for the effects of the co-variates on health care market outcomes are left out of this paper due to space constraint, but will be reported in a subsequent research article. However the female case described here complements the extensive literature on inter-generational co-residence and female labor market outcomes as previously mentioned.

\section{Conclusion}

Prior to the 2008 financial crises, many studies evidenced a decline of Inter-generational coresidence as a social phenomenon typically involving both affective ties and more instrumental forms of support such as financial resources or child care in the USA. With the advent of the financial crises and the resulting decrease in financial autonomy however, many have resulted to direct and direct family support to smooth out consumption needs. This analysis by focusing on the period post-ACA enforcement, has concerned itself with investigating the effects of intergenerational co-residence on health care market and labor market outcomes to see whether or 
not living under the same roof with at least one parent matters in health care market, and labor market behaviors post-Affordable-care act USA.

In order to achieve this goal, the study relied on data from the 2015-2016 National Health Interview Surveys, and an analytical strategy that involved not only looking at the gender differences in inter-generational co-residence effects in the two markets (Health care market, and Labor market), but also accounting for co-residence endogeneity following the recent literature on co-residence. Unlike the recent literature that relied on instrumental variables methods to resolve the endogeneity issue, the current study adopted a switching regression approach, defining intergenerational co-residence as an endogenous selection process using a binary probit equation, and modeled jointly with the extensive margins (Access, Work status) and intensive margins (Usage, Full-time) in the health care market and labor market respectively. This modeling approach resulted in a recursive trivariate probit model for each market, and estimated using penalized maximum likelihood methods.

In relation to the questions raised and formulated hypothesis in the introduction, the results showed that the likelihood of inter-generational co-residence is significantly different for males and females in the USA during 2015-2016. More specifically, it was found that compared to males, females are $7.6 \%$ (in health care market) and 8.5\% (in labor market) less likely to live under the same roof with parent at least one parent, therefore providing enough evidence to safely reject the first hypothesis $H_{0}(1)$.

In relation to the second hypothesis, the results showed that compared to non-co-residing individuals, those living under the same roof with at least one parent, while spending $69.7 \%$ more on health care annually are 1.22 times more likely to access health care, but $31 \%$ less likely to use health care intensively (10 times or more) during the year. Therefore supporting the idea that inter-generational co-residence affects significantly health care access, usage and expenditure in post-ACA USA, and hence providing enough evidence to safely reject the second hypothesis $H_{0}(2)$.

In relation to the third hypothesis, the results showed that the effects of inter-generational co-residence on health care access, usage and expenditure differ between the males and females sub-samples. In fact, although consistent effects (signs and significances) are observed in the case of health care access and expenditure, in the case of usage however, only in the females' sub-sample is the effect of co-residence significant. These results suggest that although co-residence reduces significantly health care usage among females, it has no significant impact on health care usage among males; as such we can safely reject the third hypothesis $H_{0}(3)$, and conclude the evidence is enough to suggest the presence of gender inequalities in co-residence effect on health care usage in post-ACA USA.

Now considering the fourth hypothesis, the results showed that compared to non-co-residing individuals, those living under the same roof with at least one parent are not significantly different in their likelihood of labor force participation, however they are 1.52 times less likely to work full 
time once they decide to participate, and also spend about 55.4\% less time working in the labor market. Therefore supporting the idea that inter-generational co-residence significantly affects individuals' full-time work status and time spent working in post-ACA USA, and hence providing enough evidence to also reject the fourth hypothesis $H_{0}(4)$.

With regards to the last hypothesis, the results showed an heterogeneity in the effects of intergenerational co-residence on labor market participation, full-time work status and time spent working between the males and females sub-samples. In fact, although fairly similar effects are observed in the case of full-time participation and time spent working, in terms of whether or not to participate in the labor market, only among females is the effect of co-residence significant. These results suggest that although co-residence reduces significantly the likelihood of labor force participation among females, it has no significant impact on labor force participation among males; as such we can safely reject the fifth hypothesis $H_{0}(5)$, and conclude the evidence is enough to suggest the presence of gender inequalities in co-residence effect on labor force participation in post-ACA USA.

Overall the results indicate that ACA by reorganizing the US health care market, has succeeded in reducing significantly disparities in health care access among males and females based on race, region of residence, place of birth, and citizenship. Although ACA individual mandate made gender based premium discrimination illegal, allowing women to pay the same health insurance premium costs as men "ceteris paribus", much still remain to be done in terms of policy, since reasonable evidence is still found of not only significant differences in inter-generational co-residence status between males and females, but also significant inequalities in the effects of co-residence in health care market, and labor market outcomes in post-ACA USA. Congress members and other US policy makers might therefore gain in focusing current and future policy efforts in reducing further the observed gender inequalities in co-residence effects on health care usage, and labor force participation in the country. 


\section{References}

Allison, John R (2017), The Affordable Care Act and Prescription Drug Expenditures: A Comparison of the Near Elderly and Elderly, PhD thesis, Georgetown University.

Antwi, Yaa Akosa, Asako S Moriya and Kosali I Simon (2015), 'Access to health insurance and the use of inpatient medical care: evidence from the affordable care act young adult mandate', Journal of health economics 39, 171-187.

Antwi, Yaa Akosa, Asako S Moriya, Kosali Simon and Benjamin D Sommers (2015), 'Changes in emergency department use among young adults after the patient protection and affordable care act's dependent coverage provision', Annals of emergency medicine 65(6), 664-672.

Azari, Hossein, David Parks and Lirong Xia (2012), Random utility theory for social choice, in 'Advances in Neural Information Processing Systems', pp. 126-134.

Baltagi, Badi H and Francesco Moscone (2010), 'Health care expenditure and income in the oecd reconsidered: Evidence from panel data', Economic Modelling 27(4), 804-811.

Barbaresco, Silvia, Charles J Courtemanche and Yanling Qi (2015), 'Impacts of the affordable care act dependent coverage provision on health-related outcomes of young adults', Journal of health economics 40, 54-68.

Bauer, Ursula E, Peter A Briss, Richard A Goodman and Barbara A Bowman (2014), 'Prevention of chronic disease in the 21st century: elimination of the leading preventable causes of premature death and disability in the usa', The Lancet 384(9937), 45-52.

Blackwell, Debra L, Jacqueline W Lucas and Tainya C Clarke (2014), 'Summary health statistics for us adults: national health interview survey, 2012.', Vital and health statistics. Series 10, Data from the National Health Survey (260), 1-161.

Bordoloi, Sudarshana and Raju J Das (2017), 'Modernization theory', The International Encyclopedia of Geography .

Brady, Michelle (2018), The role of informal childcare in mothers' experiences of care and employment: A qualitative lifecourse analysis, in 'Lone Parenthood in the Life Course', Springer, pp. 237-255.

Bruno, Giovanni SF, Misbah Choudhry Tanveer, Enrico Marelli and Marcello Signorelli (2017), 'The short-and long-run impacts of financial crises on youth unemployment in oecd countries', Applied Economics 49(34), 3372-3394. 
Cameron, A Colin and Pravin K Trivedi (2005), Microeconometrics: methods and applications, Cambridge university press.

Cecchini, Michele and Franco Sassi (2015), 'Preventing obesity in the usa: impact on health service utilization and costs', Pharmacoeconomics 33(7), 765-776.

Cho, Yoonyoung and David Newhouse (2013), 'How did the great recession affect different types of workers? evidence from 17 middle-income countries', World Development 41, 31-50.

Christopher, Andrea S and Dominic Caruso (2015), 'Promoting health as a human right in the post-aca united states', AMA journal of ethics $\mathbf{1 7}(10), 958$.

Chua, Kao-Ping and Benjamin D Sommers (2014), 'Changes in health and medical spending among young adults under health reform', Jama 311(23), 2437-2439.

Cohen, Robin A and Michael E Martinez (2014), 'Health insurance coverage: early release of estimates from the national health interview survey, january-march 2014', National Center for Health Statistics, Centers for Disease Control and Prevention.

Colman, Gregory and Dhaval Dave (2018), 'It's about time: effects of the affordable care act dependent coverage mandate on time use', Contemporary Economic Policy 36(1), 44-58.

Coltrane, Scott (2000), 'Research on household labor: Modeling and measuring the social embeddedness of routine family work', Journal of Marriage and family 62(4), 1208-1233.

Compton, Janice and Robert A Pollak (2014), 'Family proximity, childcare, and women's labor force attachment', Journal of Urban Economics 79, 72-90.

Compton, Janice and Robert A Pollak (2015), 'Proximity and co-residence of adult children and their parents in the united states: Descriptions and correlates', Annals of Economics and Statistics/Annales d'Économie et de Statistique (117-118), 91-114.

Courtin, Emilie and Mauricio Avendano (2016), 'Under one roof: The effect of co-residing with adult children on depression in later life', Social Science $\&$ Medicine 168, 140-149.

Dallmann-Papke, Vicki and Kathy Scott (2016), 'The medicare wellness exam: A population health innovation for the older adult', Nurse Leader 14(5), 302-303.

DeNavas-Walt, Carmen (2010), Income, poverty, and health insurance coverage in the United States (2005), Diane Publishing. 
Depew, Briggs (2015), 'The effect of state dependent mandate laws on the labor supply decisions of young adults', Journal of health economics 39, 123-134.

Díaz, Antonia and M Dolores (2005), 'Family ties and labor supply', investigaciones económicas $\mathbf{2 9}(2)$.

DiSantostefano, Jan (2011), 'Annual wellness visit for medicare beneficiaries', The Journal for Nurse Practitioners 7(5), 421-422.

Dolan, Ricki Marie Sears (2016), Essays on the economics of health insurance, labor markets, and migration, $\mathrm{PhD}$ thesis.

Duggan, Mark, Gopi Shah Goda and Emilie Jackson (2017), 'The effects of the affordable care act on health insurance coverage and labor market outcomes'.

Emran, M Shahe and Forhad Shilpi (2017), 'Estimating intergenerational mobility with incomplete data: Coresidency and truncation bias in rank-based relative and absolute mobility measures'.

Emran, M Shahe, William H Greene and Forhad Shilpi (2015), 'When measure matters: coresident sample selection bias in estimating intergenerational mobility in developing countries'.

Even, William E and David A Macpherson (2016), 'The affordable care act and the growth of involuntary part-time employment'.

Gaudette, Étienne, Gwyn C Pauley and Julie Zissimopoulos (2016), 'Lifetime consequences of early and midlife access to health insurance: A review'.

Gorry, Devon and Diana W Thomas (2017), 'Regulation and the cost of childcare', Applied Economics pp. 1-10.

Grundy, Emily (2005), 'Reciprocity in relationships: socio-economic and health influences on intergenerational exchanges between third age parents and their adult children in great britain', The British journal of sociology 56(2), 233-255.

Han, Xuesong, K Robin Yabroff, Gery P Guy, Zhiyuan Zheng and Ahmedin Jemal (2015), 'Has recommended preventive service use increased after elimination of cost-sharing as part of the affordable care act in the united states?', Preventive medicine 78, 85-91.

Harrington, Scott E (2010), 'Us health-care reform: The patient protection and affordable care act', Journal of Risk and Insurance 77(3), 703-708. 
Heckman, James J. (1979), 'Sample selection bias as specification error', Econometrica 47(1), 153161.

Heim, Bradley, Ithai Lurie and Kosali Simon (2015), 'The impact of the affordable care act young adult provision on labor market outcomes: evidence from tax data', Tax Policy and Economy 29(1), 133-157.

Hey, John D and Chris Orme (1994), 'Investigating generalizations of expected utility theory using experimental data', Econometrica: Journal of the Econometric Society pp. 1291-1326.

Jaffe, Harold W and Thomas R Frieden (2014), 'Improving health in the usa: progress and challenges', The Lancet 384(9937), 3-5.

Jensen, Gail A, Ramzi G Salloum, Jianhui Hu, Nasim Baghban Ferdows and Wassim Tarraf (2015), 'A slow start: Use of preventive services among seniors following the affordable care act's enhancement of medicare benefits in the us', Preventive medicine 76, 37-42.

Keene, Jennifer Reid and Christie D Batson (2010), 'Under one roof: A review of research on intergenerational coresidence and multigenerational households in the united states', Sociology Compass 4(8), 642-657.

Khanna, Gaurav and David Newhouse (2013), Fewer Jobs or Smaller Paychecks?: Aggregate Crisis Impacts in Selected Middle-Income, pp. 17-36.

Kimmel, Jean (1998), 'Child care costs as a barrier to employment for single and married mothers', The Review of Economics and Statistics 80(2), 287-299.

Koh, Howard K, Julie J Piotrowski, Shiriki Kumanyika and Jonathan E Fielding (2011), 'Healthy people: a 2020 vision for the social determinants approach', Health Education $\&$ Behavior $38(6), 551-557$.

Koh, Howard K and Kathleen G Sebelius (2010), 'Promoting prevention through the affordable care act', New England Journal of Medicine 363(14), 1296-1299.

Kolodinsky, Jane and Lee Shirey (2000), 'The impact of living with an elder parent on adult daughter's labor supply and hours of work', Journal of Family and Economic Issues 21(2), 149175.

Landmann, Andreas, Helke Seitz and Susan Steiner (2017), 'Intergenerational coresidence and female labour supply'. 
Lee, Lung-Fei and Robert H Porter (1984), 'Switching regression models with imperfect sample separation information-with an application on cartel stability', Econometrica: Journal of the Econometric Society pp. 391-418.

Lenhart, Otto and Vinish Shrestha (2016), The effect of the health insurance mandate on labor market activity and time allocation: Evidence from the federal dependent coverage provision, in 'Forum for Health Economics and Policy'.

Lilly, Meredith B, Audrey Laporte and Peter C Coyte (2007), 'Labor market work and home care's unpaid caregivers: a systematic review of labor force participation rates, predictors of labor market withdrawal, and hours of work', The Milbank Quarterly 85(4), 641-690.

Lorenzoni, Luca, Annalisa Belloni and Franco Sassi (2014), 'Health-care expenditure and health policy in the usa versus other high-spending oecd countries', The Lancet 384(9937), 83-92.

Madrian, Brigitte (2006), The us health care system and labor markets, Technical report, National Bureau of Economic Research.

Mandell, Nancy and Ann H Kim (2017), '3. intergenerational relations in later life families', The Sandwich Generation: Caring for Oneself and Others at Home and at Work p. 62.

Manski, Charles F (1977), 'The structure of random utility models', Theory and decision 8(3), 229254.

Marra, Giampiero and Rosalba Radice (2017), 'A joint regression modeling framework for analyzing bivariate binary data in r', Dependence Modeling 5(1), 268-294.

Maurer-Fazio, Margaret, Rachel Connelly, Lan Chen and Lixin Tang (2011), 'Childcare, eldercare, and labor force participation of married women in urban china, 1982-2000', Journal of Human Resources 46(2), 261-294.

McGarry, Kathleen and Robert F Schoeni (2000), 'Social security, economic growth, and the rise in elderly widows' independence in the twentieth century', Demography 37(2), 221-236.

Mongin, Philippe (1997), 'Expected utility theory', Handbook of economic methodology $\mathbf{3 4 2 3 5 0 .}$

Morreale, M (1998), 'Fact sheet: What factors can influence health care utilization?', Nursing Effectiveness, Utilization and Outcomes Research Unit. McMaster University, University of Toronto . 
National Center for Health Statistics and others (2015), '2015 national health interview survey (nhis) public use data release: Nhis survey description', Division of Health Interview Statistics, National Center for Health Statistics, Centers for Disease Control and Prevention. Available from the NHIS Web site (www. cdc. gov/nchs/nhis. htm).

National Center for Health Statistics and others (2016), '2016 national health interview survey (nhis) public use data release: Nhis survey description', Division of Health Interview Statistics, National Center for Health Statistics, Centers for Disease Control and Prevention. Available from the NHIS Web site (www. cdc. gov/nchs/nhis. htm).

Niankara, Ibrahim (2017), 'A risk based random utility model for population based discrete choice analysis in health economics with applications in modeling patients choices among medical treatment plans', Global Business \& Economics Anthology (GBEA), ISSN: 1553-1392 (1), 2739.

Niankara, Ibrahim (2018), 'Evaluating health consumers' preferences stability through joint estimation of revealed and stated health insurance preferences data', International Journal of Economics and Business Research 15(2), 236-256.

Oshio, Takashi (2006), 'Coresidence with parents and a wife's decision to work in japan akiko s. oishi', The Japanese Journal of Social Security Policy 5(1).

Parsons, Van L, Christopher L Moriarity, Kimball Jonas, Thomas F Moore, Karen E Davis and Linda Tompkins (2014), 'Design and estimation for the national health interview survey, 20062015 .

Peng, Yuan (2009), 'Modernization theory: from historical misunderstanding to realistic development: a review of a new thesis on modernization', Chinese Studies in History 43(1), 37-45.

Phelps, Charles E (2017), Health economics, Routledge.

Pollitz, Karen, Jennifer Tolbert and Rosa Ma (2015), '2015 survey of health insurance marketplace assister programs and brokers', Princeton, NJ: Kaiser Family Foundation .

Proctor, Bernadette D (2016), 'Income, poverty, and health insurance coverage in the united states: 2010', Report P60-256. September. Census Bureau .

R Core Team (2015), R: A Language and Environment for Statistical Computing, R Foundation for Statistical Computing, Vienna, Austria.

URL: https://www.R-project.org/ 
Romero, Mary (2002), Maid in the USA, Psychology Press.

Rosenfeld, Michael J (2006), 'Young adulthood as a factor in social change in the united states', Population and Development Review 32(1), 27-51.

Rosenstock, Irwin M (2005), 'Why people use health services', The Milbank Quarterly 83(4).

Ruggles, Steven (2007), 'The decline of intergenerational coresidence in the united states, 1850 to 2000', American sociological review 72(6), 964-989.

Ruggles, Steven (2011), 'Intergenerational coresidence and family transitions in the united states, 1850-1880', Journal of Marriage and Family 73(1), 136-148.

Rutledge, Matthew S (2016), 'The interconnected relationships of health insurance, health, and labor market outcomes'.

Sasaki, Masaru (2002), 'The causal effect of family structure on labor force participation among japanese married women', Journal of Human Resources pp. 429-440.

Schoen, Cathy (2016), The Affordable Care Act and the US economy: A five-year perspective, Commonwealth Fund.

Scott, John W, Ali Salim, Benjamin D Sommers, Thomas C Tsai, Kirstin W Scott and Zirui Song (2015), 'Racial and regional disparities in the effect of the affordable care act's dependent coverage provision on young adult trauma patients', Journal of the American College of Surgeons $\mathbf{2 2 1}(2)$, 495-501.

Shahe Emran, M, William H Greene and Forhad Shilpi (2016), 'When measure matters: Coresidency, truncation bias, and intergenerational mobility in developing countries'.

Shaw, Frederic E, Chisara N Asomugha, Patrick H Conway and Andrew S Rein (2014), 'The patient protection and affordable care act: opportunities for prevention and public health', The Lancet 384(9937), 75-82.

Shen, Ke, Ping Yan and Yi Zeng (2016), 'Coresidence with elderly parents and female labor supply in china', Demographic Research 35, 645.

Shrestha, Vinish and Otto Lenhart (2015), 'The effect of health insurance mandate on labor market activity and time allocation: Evidence from the federal dependent coverage provision'.

Sommers, Benjamin D, Munira Z Gunja, Kenneth Finegold and Thomas Musco (2015), 'Changes in self-reported insurance coverage, access to care, and health under the affordable care act', Jama 314(4), 366-374. 
Sommers, Benjamin D, Thomas Buchmueller, Sandra L Decker, Colleen Carey and Richard Kronick (2012), 'The affordable care act has led to significant gains in health insurance and access to care for young adults', Health affairs 32(1), 165-174.

Sorgente, Angela and Margherita Lanz (2017), 'Emerging adults' financial well-being: A scoping review', Adolescent Research Review pp. 1-38.

Stanton, Mark W and MK Rutherford (2006), The high concentration of US health care expenditures, Agency for Healthcare Research and Quality Washington, DC.

Swartz, Teresa Toguchi (2009), 'Intergenerational family relations in adulthood: Patterns, variations, and implications in the contemporary united states', Annual Review of Sociology 35, 191212 .

Tanveer Choudhry, Misbah, Enrico Marelli and Marcello Signorelli (2012), 'Youth unemployment rate and impact of financial crises', International journal of manpower 33(1), 76-95.

Verick, Sher (2009), 'Who is hit hardest during a financial crisis? the vulnerability of young men and women to unemployment in an economic downturn'.

Verick, Sher and Iyanatul Islam (2010), 'The great recession of 2008-2009: causes, consequences and policy responses'.

Wallace, Jacob and Benjamin D Sommers (2015), 'Effect of dependent coverage expansion of the affordable care act on health and access to care for young adults', JAMA pediatrics 169(5), 495497.

Wojtys, Malgorzata, Giampiero Marra and Rosalba Radice (2016), 'Copula regression spline sample selection models: the r package semiparsamplesel', Journal of Statistical Software 71(6).

Zamarro, Gema (2011), 'Family labor participation and child care decisions: The role of grannies.', RAND Labor and Population working paper series - WR-833. 
Table 1: Descriptive Statistics for the variables used in the analysis

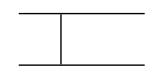

Source: 2015-2016 National Health Interview Surveys (NHIS)

Table 2: Chi-square test and Conditional Frequency Distribution for Inter-generational Co-residence Status

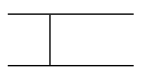

Source: 2015-2016 National Health Interview Surveys (NHIS)

Table 3: Factors explaining USA co-residency, conditional on Health Care Market and Labor Market Outcomes

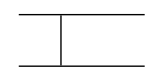

Source: 2015-2016 National Health Interview Surveys (NHIS) 
Table 4: Inter-generational co-residence and US health care market, and labor market outcomes across sex

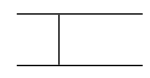

Source: 2015-2016 National Health Interview Surveys (NHIS) 